\title{
Second-generation colon capsule endoscopy for detection of colorectal polyps: A meta-analysis
}

\author{
Samira Alihosseini ${ }^{1,2}$, Aidin Aryankhesal ${ }^{3,4}$, Asma Sabermahani*5 ${ }^{(1)}$ \\ Received: 19 Aug 2018 \\ Published: 16 Jul 2020
}

Abstract

Background: Colorectal cancer counts as the third prevalent type of cancer and the fourth cause of death worldwide. The secondgeneration colon capsule endoscopy (CCE-2) is a new technology for the diagnosis of colon cancer. The aim of this review was to provide information on the diagnostic accuracy (diagnostic effectiveness) of the second-generation colon capsule endoscopy compared to colonoscopy for the diagnosis of colon cancer and disorders.

Methods: A systematic review of literature in PubMed, Scopus, Science Direct, and Cochrane Library and Iranian databases, such as MagIran, SID, Irandoc, the grey literature (via Google Scholar) was conducted on February 30, 2018. QUADAS-2 was used to assess the quality of the studies. MetaDiSc 2.0 software was used for the meta-analysis.

Results: In this review, 480 records were identified. Eight prospective cohort articles were included among which 7 included in the meta-analysis. For the diagnosis of colorectal polyps with a diameter of $6-10 \mathrm{~mm}$, the pooled sensitivity and specificity were $84 \%(95 \%$ CI, $80 \%-88 \%)$ and $88 \%(95 \% \mathrm{CI}, 85 \%-90 \%)$. For the diagnosis of $10 \mathrm{~mm}$ or bigger colorectal polyps, the pooled sensitivity and specificity were $84 \%$ (95\% CI, 76\%-89\%) and 96\% (95\% CI, 94\%-97\%). The sensitivity and specificity of the capsule in the detection of any size polyps were $93 \%(95 \%$ CI, $97 \%-84 \%)$ and $66 \%(95 \%$ CI, $48 \%-81 \%)$, respectively.

Conclusion: There is little evidence to show the accuracy of CCE-2. Nevertheless, this review showed that the second-generation colon capsule endoscopy has good accuracy in the detection of polyps and colorectal cancer among high- and middle-risk patients.

Keywords: Colon capsule endoscopy, Colonic polyp, Accuracy, CCE-2, Colonoscopy

Conflicts of Interest: None declared

Funding: This article supported by Kerman University of Medical Sciences with an approval number of IR.KMU.REC.1397.110.

*This work has been published under CC BY-NC-SA 1.0 license.

Copyright $₫$ Iran University of Medical Sciences

Cite this article as: Alihosseini S, Aryankhesal A, Sabermahani A. Second-generation colon capsule endoscopy for detection of colorectal polyps: A meta-analysis. Med J Islam Repub Iran. 2020 (16 Jul);34:81. https://doi.org/10.47176/mjiri.34.81

\section{Introduction}

Colorectal cancer counts as the third prevalent type of cancer and is the fourth cause of death across the world (1$3)$. This type of cancer usually causes delayed symptoms; hence early diagnosis through regular screening programs are very critical (4). Screening of colorectal cancer can identify cancer, pre-cancerous polyps and other abnormal disorders. The earlier is cancer detected, the easier and less

Corresponding author:Dr Asma Sabermahani, a-saber@kmu.ac.ir

1. Department of Health Services Management and Policy and Economics, School of Health Management and Information Sciences, Kerman University of Medical Sciences, Kerman, Iran

2. Think-tank Office, Iran University of Medical Sciences, Tehran, Iran

3. Health Management and Economics Research Center, Iran University of Medical Sciences, Tehran, Iran

4. Department of Health Services Management, School of Health Management and Information Sciences, Iran University of Medical Sciences, Tehran, Iran

5. Student Research Committee, Kerman University of Medical Sciences, Kerman, Iran costly is the treatment (5). By screening, the detection of pre-cancerous polyps before the onset of the disease can lead to the treatment of cancer in the early stages and before it is transmitted to the other parts of the body. Therefore, the best method for cancer prevention is the early diagnosis and treatment of abnormal disorders and polyps $(5,6)$.

Among the available methods for diagnosis of colorectal

$\uparrow$ What is "already known" in this topic:

Colorectal polyps are usually diagnosed through colonoscopy, while colon capsule endoscopy is introduced during recent years for the same indication.

\section{$\rightarrow$ What this article adds:}

Colon capsule endoscopy has better accuracy than colonoscopy in detecting colon polyps. When compared with colonoscopy, colon capsule endoscopy ends with a better experience in patients and can improve their satisfaction with the screening and diagnosis process. 
disorders, colonoscopy is known as the standard test (7). Most of the published guidelines recommend one colonoscopy per 10 years of life among people aged 50 and over (8). But due to the complications that can be caused by colonoscopy, including bleeding and perforation, it is a painful and embarrassing process, and implementation of the instruction is less welcomed by patients $(5,7)$. The secondgeneration colon capsule endoscopy (CCE-2) is a new technology for the diagnosis of colon cancer, based on the development of previous technology and clinical experience with the use of a narrow intestinal endoscopy capsule. This technology is presented as a non-invasive substitution method for large bowel examination. When it is used, it does not require sedative and analgesic procedures (9). Considering the importance of fast and accurate diagnosis of polyps and colon cancer and the use of an appropriate and effective method, the aim of this review is to provide information on the diagnostic accuracy (diagnostic effectiveness) of the second-generation colon capsule endoscopy compared to colonoscopy for the diagnosis of colon cancer and disorders.

\section{Methods}

Since the second generation of colon capsule endoscopy was produced in 2006, after the first generation of colon capsule endoscopy (10), a systematic review of the literature including databases and website including PubMed, Scopus, Science Direct and Cochrane Library, Iranian databases, such as MagIran, SID, Irandoc and the grey literature (via Google Scholar) was done from December 27, 2006 to February 30, 2018 (the strategy for each database is listed in Appendix 1). The Medical Subject Heading $(\mathrm{MeSH})$ was used to construct the search strategy. In order to achieve the maximum number of available studies, in addition to the electronic search, hand searching was also carried out. To select the appropriate studies, two individuals independently reviewed the records and disagreements were discussed. Articles of conferences and papers other than original research were removed from our study. After completing the search, all of the published articles were transferred into EndNote X8 software, and then the duplicates were removed.

\section{Inclusion criteria}

Population: Individuals suspected of colon polyps with indication for second-generation colon capsule endoscopy and colonoscopy simultaneously.

\section{Intervention}

The second-generation colon capsule endoscopy Comparison: Colonoscopy Outcome: The desired outcome was the accuracy of the procedures in the detection of cancer and colon polyps (sensitivity and specificity and positive predictive value and negative predictive value).

\section{Study Design}

Diagnostic studies and all observational studies that performed to check the accuracy of the diagnostic tests of the two devices.

\section{Exclusion criteria}

Studies that investigated the treatment of diseases rather than colon cancer and colon polyps, along with studies that used other interventions (such as CCE-1) were excluded. Also, non-English language studies were not examined.

\section{Quality assessment}

Quality Assessment of Diagnostic Accuracy Studies (QUADAS-2) checklist (11) was used to examine the quality of the selected studies. Quality assessment criteria include patient selection bias, index test results bias, reference, and follow-up test results, and appropriate timing of tests. The table of the quality assessment of the studies is provided in Appendix 2. To assess the quality of the studies, two individuals independently reviewed the records and discussed the disagreement.

\section{Data Extraction}

To collect information from the included articles, a predesigned checklist was used to extracted data. After completing, the table was checked by a second author. The data extraction table contained title, author, year of publication, journal name, setting of the study, study population, type of study, number of subjects studied, prevalence of polyps, level of bowel cleansing, outcomes (i.e., sensitivity or specificity), conclusion and the quality of the study. Then, based on the inclusion and exclusion criteria, the articles were selected and after studying the title of records, some of the irrelevant articles were excluded, also after checking the abstracts at this stage, a number of other articles were excluded. Moreover, based on the full text of the articles some of the articles were excluded. After these assessments, remaining records were critically reviewed on the basis of the checklist QUADAS-2. All of the studies reviewed by two individuals independently and the cases of disagreement were discussed.

\section{Statistical Analysis}

We used Cochran's $\mathrm{Q}$ test and $\mathrm{I}^{2}$ index to examine the heterogeneity of the studies. If there was any heterogeneity, the random model effect was applied to solve the heterogeneity problem. The heterogeneity was categorized in three levels ( $\mathrm{I}^{2}<25 \%$ : low, $25 \%<\mathrm{I}^{2}<75 \%$ : moderate, and $\mathrm{I}^{2}$ $>75 \%$ : high) $(12,13)$. The effectiveness of interventions was done through studying the consequences such as sensitivity and specificity. Using the same type of indicators extracted from the included studies, data pooling was done in MetaDiSc 2.0 software, which is usually used for the meta-analysis of diagnostic value studies. The hierarchical summary receiver operating characteristic (HSROC) model has been proposed in this study and the results were plotted using the Forest plot and SROC curves.

\section{Results}

A total of 472 records were retrieved from the electronic databases and 8 articles were found through the hand searching.

In Figure 1, the screening process is presented in accordance with the PRISMA standard. The revealed articles were evaluated for inclusion/exclusion criteria independently by 


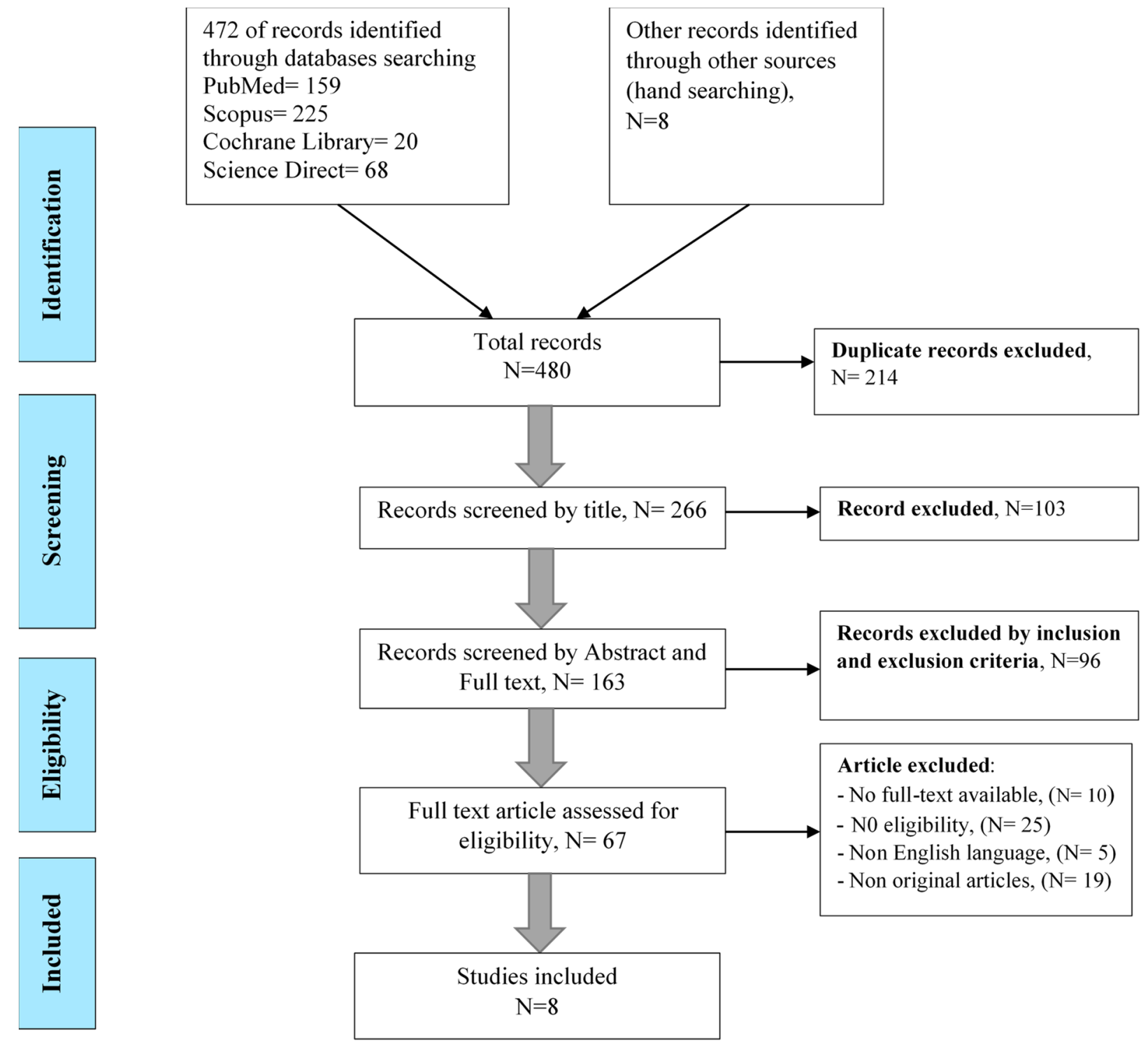

Fig. 1. The process of screening articles according to the PRISMA standard

two researchers. No study was omitted after the quality assessment and all the selected studies were entered into the final analysis.

\section{Study Features}

Eight prospective cohort articles (14-21) were included. All studies were written in English. The total number of participants was 1238, of whom 611 were men and 627 women. The largest sample size was 689 (17), while the smallest study included only 23 participants (18). The average age of participants in the studies ranged from 49.8 (20) to 62.5 (19). The level of bowel cleaning was appropriate in all studies. A summary of the characteristics of the included studies is shown in Table 1.

Diagnostic Accuracy of second-generation colon capsule endoscopy

In all studies, the second-generation colon capsule endoscopy was the intervention test. In three studies $(14,15,19)$, the reference test was an optical colonoscopy, and in the remaining (16-18, 20, 21), conventional colonoscopy was the reference test. Colonoscopy was performed while the operators and physicians were blind to the results of the capsule test. Five studies reported the sensitivity and specificity of the endoscopic colon to detect colorectal polyps in dimensions of at least $6 \leq \mathrm{mm}$ and $10 \leq \mathrm{mm}$ in each patient $(14,16,17,20,21)$. Two papers also reported the sensitivity and specificity of the capsule in the diagnosis of colorectal polyps at any size $(18,19)$. Since one of the papers (15) intended to diagnose a specific type of tumor, which was incompatible with the other papers, the related results are reported separately and narratively. The polyp-matching algorithms differed between the included studies which are summarized in Table 2.

\section{Meta-analysis results}

For the diagnosis of colorectal polyps with a diameter of $6 \mathrm{~mm}$ or larger, the pooled sensitivity and specificity were 


\begin{tabular}{|c|c|c|c|c|}
\hline Study & Country & Population & Index test & Gold standard \\
\hline $\begin{array}{l}\text { Parodi et al. } 2018 \\
\text { (13) }\end{array}$ & Italy, France & $\begin{array}{c}\text { Mean age } 57 \text { y } \\
\text { (range 26-82); } 97 \text { female, } 80 \text { male }\end{array}$ & CCE-2* & $\mathrm{OC}^{* *}$ \\
\hline $\begin{array}{l}\text { Igawa et al. } 2017 \\
\text { (14) }\end{array}$ & Japan & $\begin{array}{l}\text { Mean age } 59 \text { y } \\
6 \text { female, } 24 \text { male }\end{array}$ & CCE-2 & $\mathrm{OC}$ \\
\hline $\begin{array}{l}\text { Douglas R Morgan et al. } \\
2016(15)\end{array}$ & USA & $\begin{array}{c}\text { Mean age } 60.2 \text { y } \\
\text { (range 32-70); } 27 \text { female, } 23 \text { male }\end{array}$ & CCE-2 & $\mathrm{CC}$ \\
\hline $\begin{array}{l}\text { Douglas K. Rex et al. } \\
2015 \text { (16) }\end{array}$ & USA, Israel & $\begin{array}{c}\text { Mean age } 57 \text { y } \\
386 \text { female, } 303 \text { male }\end{array}$ & CCE-2 & $\mathrm{CC} * * *$ \\
\hline $\begin{array}{l}\text { Alexander F Hagel, } \\
\text { et al. } 2014 \text { (17) }\end{array}$ & Germany & $\begin{array}{c}\text { Mean age } 51 \text { y } \\
\text { (range } 24-75 \text { y); } 10 \text { female, } 14 \text { male }\end{array}$ & CCE-2 & $\mathrm{CC}$ \\
\hline $\begin{array}{l}\text { Holleran et al. } \\
2014(18)\end{array}$ & Ireland & $\begin{array}{c}\text { Mean age } 62.5 \mathrm{y} \\
\text { (SD 5.8 y); } 28 \text { female, } 34 \text { male }\end{array}$ & CCE-2 & $\mathrm{OC}$ \\
\hline $\begin{array}{l}\text { Spada et al. } \\
2011(19)\end{array}$ & Europe & $\begin{array}{c}\text { Mean age } 60 \text { y } \\
\text { (SD } 9 \text { y); } 45 \text { female, } 72 \text { male }\end{array}$ & CCE-2 & $\mathrm{CC}$ \\
\hline $\begin{array}{l}\text { Eliakim et al. } \\
2009(20)\end{array}$ & Israel & $\begin{array}{l}\text { Mean age } 49.8 \text { y } \\
\text { (range } 18-57 \text { y); } 33 \text { female, } 65 \text { male }\end{array}$ & CCE-2 & $\mathrm{CC}$ \\
\hline \multicolumn{5}{|c|}{ *Colon Capsule Endoscopy-2, **Optical Colonoscopy, $* * *$ Conventional Colonoscopy } \\
\hline Study & Diagnostic accuracy data reported & Sensitivity (95\% confidence) & \multicolumn{2}{|c|}{ Specificity (95\% confidence) } \\
\hline Parodi (2018) & $\begin{array}{c}\text { Polyp } 6 \leq \\
\text { Polyp } 10 \leq\end{array}$ & $\begin{array}{l}91 \%(71.9-96.1) \\
89 \%(71.9-96.1)\end{array}$ & \multicolumn{2}{|c|}{$88 \%(81.5-93)$} \\
\hline Morgan (2016) & $\begin{array}{l}\text { Polyp } 6 \leq \\
\text { Polyp } 10 \leq\end{array}$ & $\begin{array}{c}93 \%(66-99.7) \\
100 \%(56.1-100)\end{array}$ & \multicolumn{2}{|c|}{$80 \%(62.5-90.9)$} \\
\hline $\operatorname{Rex}(2015)$ & $\begin{array}{l}\text { Polyp } 6 \leq \\
\text { Polyp } 10 \leq\end{array}$ & $\begin{array}{l}81 \%(82-90) \\
80 \%(77-92)\end{array}$ & \multicolumn{2}{|c|}{$93 \%(92-96)$} \\
\hline Holleran (2014) & Polyp in any size & $95 \%(81-99)$ & \multicolumn{2}{|c|}{$65 \%(44-83)$} \\
\hline Hagel (2014) & Polyp in any size & $90.9 \%(85-100)$ & \multicolumn{2}{|c|}{$67.6 \%(36-98)$} \\
\hline Spada (2011) & Polyp $6 \leq$ & $84 \%(74-95)$ & \multicolumn{2}{|c|}{$64 \%(52-76)$} \\
\hline \multirow{3}{*}{ Eliakim (2009) } & Polyp $10 \leq$ & $88 \%(76-99)$ & \multicolumn{2}{|c|}{$95 \%(90-100)$} \\
\hline & Polyp $6 \leq$ & $89 \%(70-97)$ & \multicolumn{2}{|c|}{$76 \%(72-78)$} \\
\hline & Polyp $10 \leq$ & $88 \%(56-98)$ & \multicolumn{2}{|c|}{$89 \%(86-90)$} \\
\hline
\end{tabular}

$84 \%$ (95\% CI, 80\%-88\%) and 88\% (CI 95\%, 85\%-90\%) respectively (Fig. 2 A). The $\mathrm{I}^{2}$ coefficient for the heterogeneity of sensitivity was $19.5 \%(p=0.29)$, which shows no heterogeneity. However, the heterogeneity of the specificity was $91 \%(p<0.001)$, which means obvious significant heterogeneity.

For the diagnosis of $10 \mathrm{~mm}$ or larger colorectal polyps, as (Fig. 2 B) demonstrates, the pooled sensitivity was $84 \%$ (95\% CI, 76\% -89\%) and the specificity was 96\% (95\% CI, $94 \%-97 \%)$. The $\mathrm{I}^{2}$ coefficient for the heterogeneity of sensitivity was $0.0 \%$ and for specificity $64 \%$. The p-value for sensitivity and specificity was 0.40 and 0.02 respectively, which indicate significant and moderate to high heterogeneity in the specificity results.

The sensitivity and specificity of the capsule in the detection of any size of polyp were 93\% (95\% CI, 84\%-97\%) and $66 \%$ (95\% CI, 48\%-81\%), respectively (Fig. 2 C). The $\mathrm{I}^{2}$ heterogeneity coefficient for both sensitivity and characteristic was zero percent ( $\mathrm{p}=0.54$ and 0.94 respectively) which indicate no heterogeneity.

\section{Optimal sensitivity and specificity point for the diagno-} sis of polyps

As the SROC curve in Figure 3 shows, the optimal sensitivity and specificity in detecting a polyp of $6 \mathrm{~mm}$ or larger is about $87 \%$. This means that the correct diagnosis occurs when $87 \%$ of patients are correctly diagnosed, and $87 \%$ of healthy people are also diagnosed as non-patients.

The SROC curve in Figure 4 shows that the optimal sensitivity and specificity in detecting a $10 \mathrm{~mm}$ or larger polyp is about $91 \%$. This means that the correct diagnosis is made when $91 \%$ of patients are correctly diagnosed and $91 \%$ of
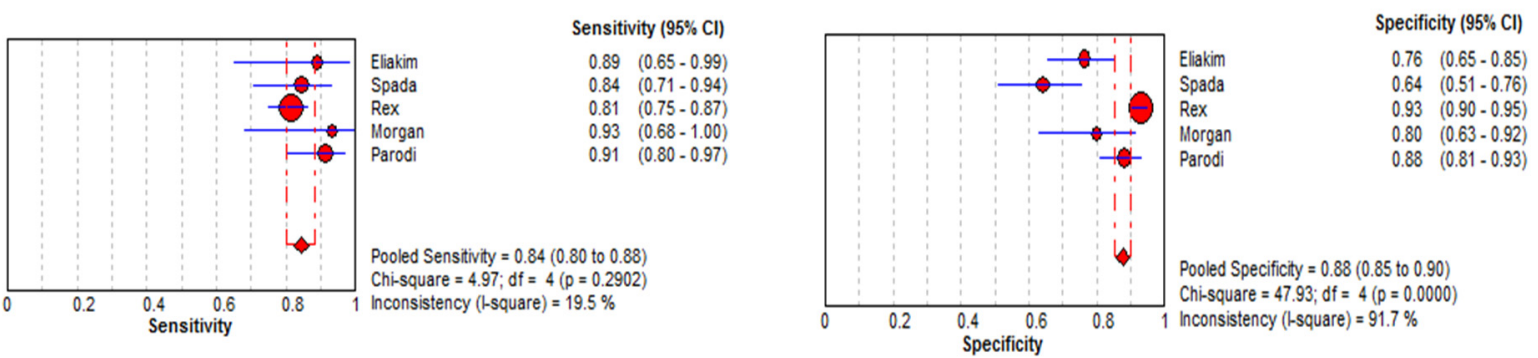

A. Detection of polyps $6 \mathrm{~mm}$ or larger

Fig. 2. Forest plots of the sensitivity and specificity of second-generation colon capsule endoscopy in the detection of colorectal polyps of varying sizes 

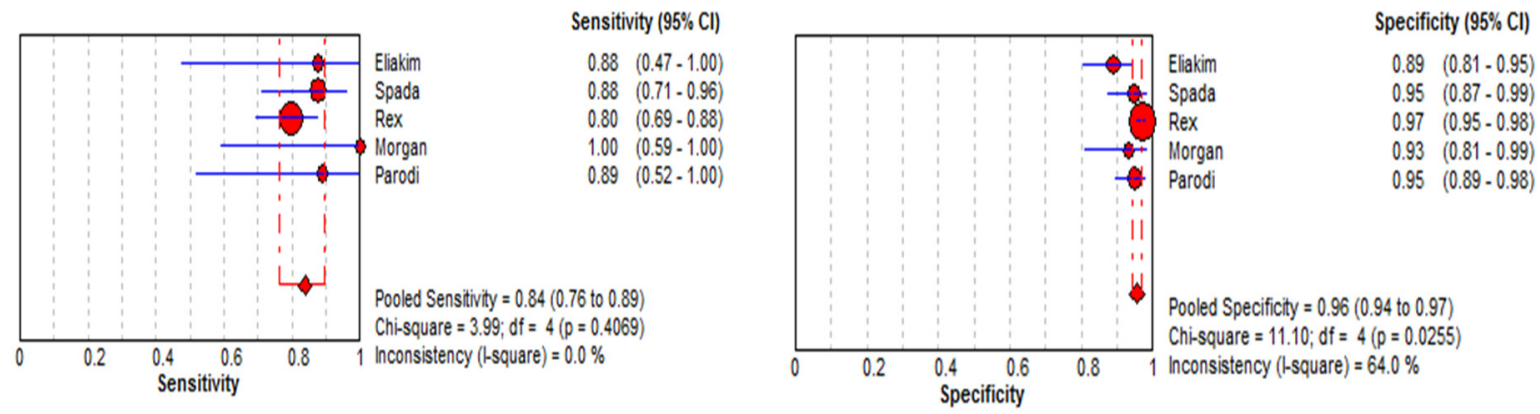

B. Detection of polyp $10 \mathrm{~mm}$ or larger
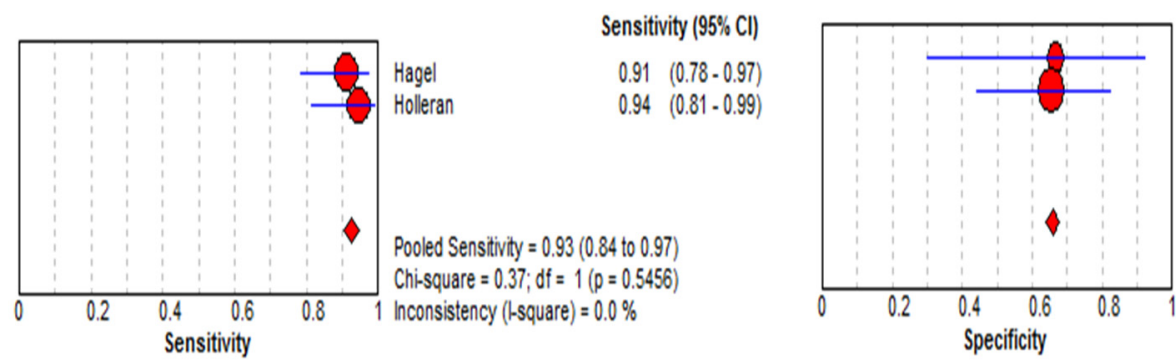

Specificity ( $95 \%$ CI)

$0.67(0.30 \cdot 0.93)$

$0.65(0.44 \cdot 0.83)$

C. Detection of any size polyp

Fig. 2. Forest plots of the sensitivity and specificity of second-generation colon capsule endoscopy in the detection of colorectal polyps of varying sizes

healthy people are also diagnosed as non-patient. Since the number of pooled studies is less than 10 , there was no possibility of reviewing the publication bias (22).

As we mentioned previously, some findings across the papers could not get pooled through meta-analysis, which is reported separately as follows:

Parodi et al. (14) recognized the sensitivity of the capsule for the diagnosis of patients with 6-10 $\mathrm{mm}$ and $10 \mathrm{~mm}$ and larger polyp adenoma 95\% (95\% CI, 83.5\%-98.6\%) and 99.9\% (95\% CI, 72.2\%- 97.5\%). They reported a specificity of $80.3 \%(95 \% \mathrm{CI}, 72.8 \%-86.1 \%)$ and $92.3 \%(95 \% \mathrm{CI}$, $95 \%-87 \%-88 \%$ ), for those sizes respectively. In this study, the sensitivity of polyp-based capsule for the detection of adenomatous polyps of $6 \mathrm{~mm}$ or smaller, $6-10 \mathrm{~mm}$ and ones larger than $10 \mathrm{~mm}$ were $29.5 \%$ (95\% CI, $19.6 \%-41.97 \%)$, $84.4 \%(95 \% \mathrm{CI}, 73.9 \%-91.4 \%)$ and $87.5 \%(95 \% \mathrm{CI}$, $71.9 \%-95 \%)$ respectively.

Igawa et al. (15) reported the sensitivity of $81 \%$ and specificity of $100 \%$ for the capsule in detecting large tumors with positive predictive value and negative predictive values of $100 \%$ and $69 \%$, respectively. Sensitivity and specificity of the capsule for detecting LST-G were $71 \%$ and $100 \%$, respectively, and positive predictive value and negative predictive values were $100 \%$ and $92 \%$, respectively.

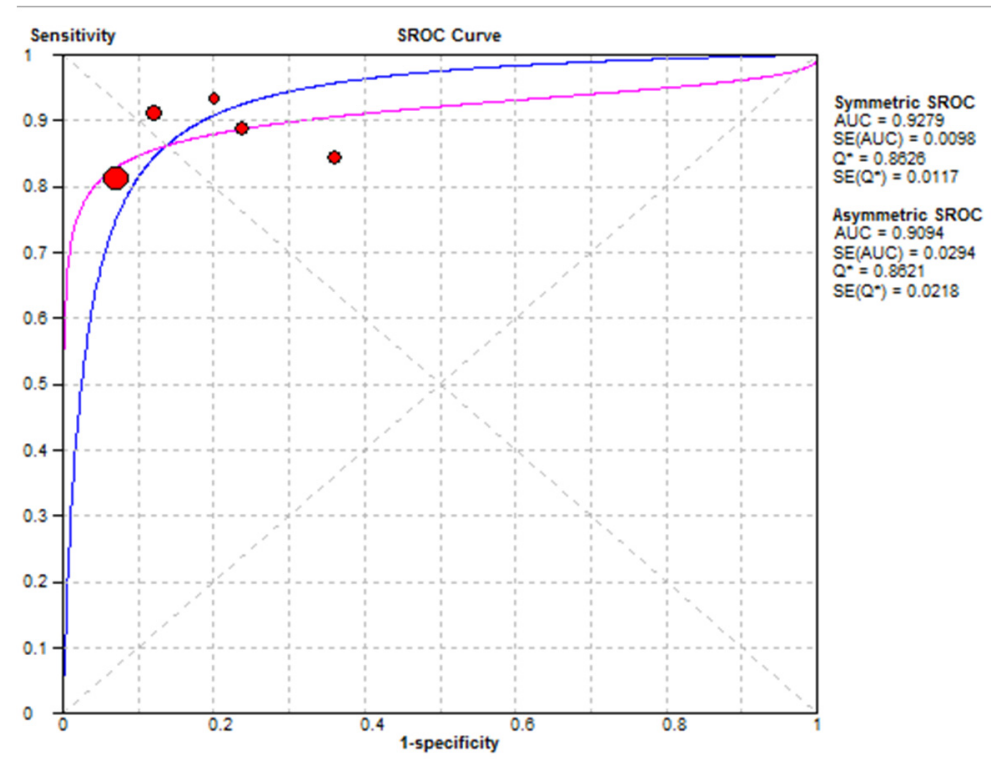

Fig. 3. The SROC curve of the endoscopic colon in the detection of $6 \mathrm{~mm}$ and larger polyps 


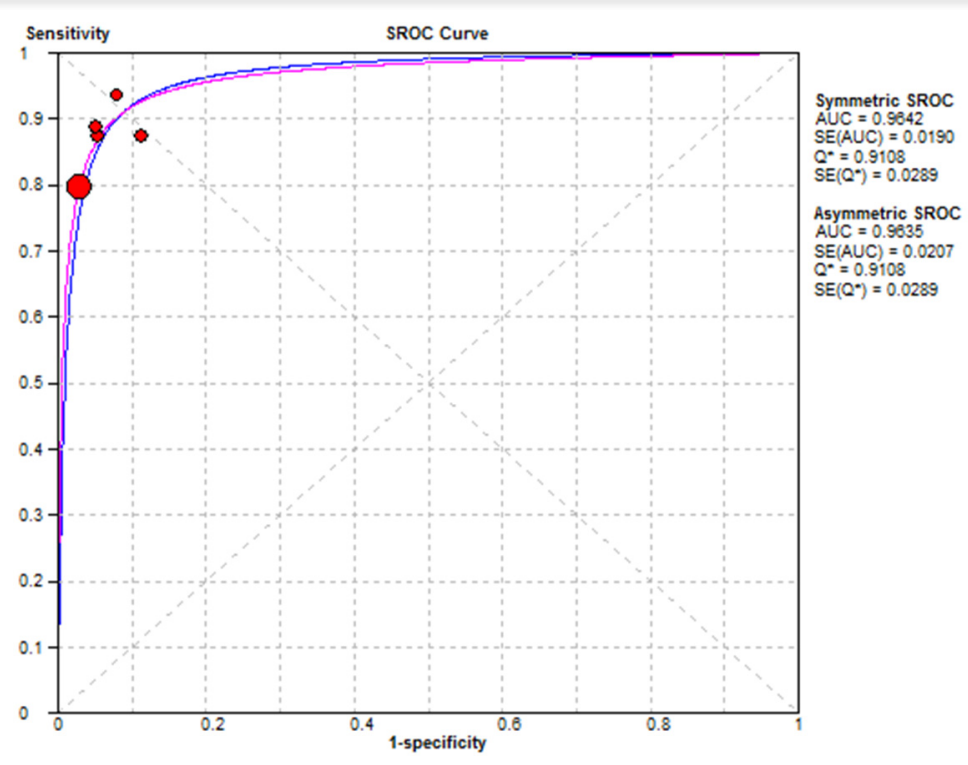

Fig. 4. The SROC curve of the endoscopic colon in the detection of $10 \mathrm{~mm}$ and larger polyps

Sensitivity and specificity of the capsule for detecting LSTNG were $86 \%$ and $100 \%$, respectively, and positive predictive value and negative predictive value were $100 \%$ and $89 \%$, respectively.

Based on Rex et al. (17) the sensitivity and specificity for detecting lesions larger than $6 \mathrm{~mm}$ were $88 \%$ and $82 \%$, repectively. The sensitivity and specificity for lesions up to $10 \mathrm{~mm}$ were $92 \%$ and $95 \%$, respectively.

Holleran et al. (19) reported a sensitivity of $89 \%$ and specificity of $96 \%$ for detecting large lesions.

Spada et al. (20) reported a sensitivity of $90 \%$ (95\% CI, $80 \%-99 \%)$ and specificity of $64 \%(95 \% \mathrm{CI}, 52 \%-76 \%)$ for the capsule in the diagnosis of neoplastic polyps larger than $6 \mathrm{~mm}$. The sensitivity and specificity for $10 \mathrm{~mm}$ polyps were $93 \%$ (95\% CI, 84\% - 100\%) and 95\% (CI 95\%, 90\% $100 \%$ ), respectively.

\section{Discussion}

The aim of this review was to provide information on the diagnostic accuracy (diagnostic effectiveness) of the second-generation colon capsule endoscopy compared to colonoscopy for the diagnosis of colon cancer and disorders. According to the evidence, endoscopy of the colon using the second-generation colon capsule endoscopy has a good sensitivity in the identification of patients with colorectal polyps. The sensitivity reported in the reviewed studies ranged 81 to $93 \%$ for $6-10 \mathrm{~mm}$ polyps and $80 \%$ to $100 \%$ for polyps of $10 \mathrm{~mm}$ and larger sizes. The specificity for these two sizes of polyps was $64-93 \%$ and $89-97 \%$, respectively $(14,16-21)$. According to our findings, for the diagnosis of colorectal polyps with a diameter of $6 \mathrm{~mm}$ or larger, the pooled sensitivity and specificity were $84 \%$ (95\% CI, 80\% -88\%) and 88\% (CI 95\%, 85\%-90\%), respectively. Also, for the diagnosis of $10 \mathrm{~mm}$ or larger colorectal polyps, the pooled sensitivity was $84 \%(95 \% \mathrm{CI}$, $76 \%-89 \%)$ and the specificity was $96 \%$ (95\% CI, 94\%$97 \%$ ). The sensitivity is above the $50 \%$ cut-off, defined by the American Cancer Society as an acceptable test for screening purposes (6).

The sensitivity and specificity results showed heterogeneity, which may be due to the difference in the amount of bowel preparation across different studies; proper bowel preparation can facilitate the diagnosis of polyps through colonic endoscopy. In the endoscopic process, the colon requires more preparation compared to colonoscopy. Some authors have suggested that, given the low number of false positives, the use of colon capsule endoscopy can reduce the number of unwanted colonoscopies (19). However, a high level of false-negative outcomes may result in late detection of colorectal cancer, which may cause a particular concern among patients with a high risk of colorectal cancer.

\section{Limitations}

This study was limited to the observational design in which the possibility of bias is unknown. Nevertheless, conducting randomized trials for the comparison of colonoscopy and CCE-2 may not be that feasible. Since we did not have access to grey literature databases in Iran, this was one of the limitations of the study too.

\section{Conclusion}

This review showed that the second-generation colon capsule endoscopy has a good accuracy in the detection of polyps and colorectal cancer among high- and middle-risk patients. It can be used as a pilot test for a specific population in Iran. Using this technology, we can increase patients' satisfaction and improve their quality of life. However, the CCE-2 lacks the ability to perform biopsy or remove the polyps, which can be done by conventional colonoscopy. 


\section{Acknowledgments}

This article is a part of an MS thesis, supported by Kerman University of Medical Sciences with an approval number of IR.KMU.REC.1397.110 issued by Kerman University of Medical Sciences.

\section{Conflict of Interests}

The authors declare that they have no competing interests.

\section{References}

1. Dolatkhah R, Somi MH, Bonyadi MJ, Asvadi Kermani I, Farassati F, Dastgiri S. Colorectal cancer in Iran: molecular epidemiology and screening strategies. J Cancer Epidemiol. 2015;2015.

2. Organization WH. Health in 2015: from MDGs to SDGs. Geneva: World Health Organization. 2015.

3. Ramazani Daryasari R, Nade Ali F, Modirian M, Arjomandpour M, Salavati F, Fazeli M, et al. National Comprehensive Cancer Control Program. Non-communicable Disease Center, Cancer Department, Ministry of Health and Medical Education (2011).

4. Kasper DL, Fauci AS, Hauser SL. Harrison's Principles of Internal Medicine, 16th Edition. Neurology. 2005;64(8):1488-9

5. Pourdastgardan R. Gastrointestinal cancers. Tehran: Green book; 2014.

6. Levin B, Lieberman DA, McFarland B, Andrews KS, Brooks D, Bond $\mathrm{J}$, et al. Screening and surveillance for the early detection of colorectal cancer and adenomatous polyps, 2008: a joint guideline from the American Cancer Society, the US Multi-Society Task Force on Colorectal Cancer, and the American College of Radiology. Gastroenterology. 2008;134(5):1570-95.

7. Sung JJ, Ng SC, Chan FK, Chiu HM, Kim HS, Matsuda T, et al. An updated Asia Pacific Consensus Recommendations on colorectal cancer screening. Gut. 2015;64(1):121-32.

8. Rex DK, Johnson DA, Anderson JC, Schoenfeld PS, Burke CA, Inadomi JM. American College of Gastroenterology Guidelines for Colorectal Cancer Screening 2008. Am J Gastroenterol. 2009;104(3):739-50.

9. Spada C, Pennazio M, Hassan C, Riccioni ME, Costamagna G. Colon capsule endoscopy. G Ital Endos Dig. 2011;34(2):103-8.

10. Hosoe N, Matsuoka K, Naganuma M, Ida Y, Ishibashi Y, Kimura K, et al. Applicability of second-generation colon capsule endoscope to ulcerative colitis: a clinical feasibility study. J Gastroenterol Hepatol. 2013;28(7):1174-9.

11. Whiting PF, Rutjes AW, Westwood ME, Mallett S, Deeks JJ, Reitsma JB, et al. QUADAS-2: a revised tool for the quality assessment of diagnostic accuracy studies. Ann Intern Med. 2011;155(8):529-36.

12. Higgins JP, Thompson SG, Deeks JJ, Altman DG. Measuring inconsistency in meta-analyses. BMJ. 2003;327(7414):557-60.

13. Ades AE, Lu G, Higgins JP. The interpretation of random-effects meta-analysis in decision models. Med Decis Making. 2005;25(6):646-54.

14. Parodi A, Vanbiervliet G, Hassan C, Hebuterne X, De Ceglie A, Filiberti RA, et al. Colon capsule endoscopy to screen for colorectal neoplasia in those with family histories of colorectal cancer. Gastrointest Endosc. 2018;87(3):695-704.

15. Igawa A, Oka S, Tanaka S, Otani I, Kunihara S, Chayama K. Evaluation for the Clinical Efficacy of Colon Capsule Endoscopy in the Detection of Laterally Spreading Tumors. Digestion. 2017;95(1):43-8.

16. Morgan DR, Malik PR, Romeo DP, Rex DK. Initial US evaluation of second-generation capsule colonoscopy for detecting colon polyps. BMJ Open Gastroenterol. 2016;3(1):e000089.

17. Rex DK, Adler SN, Aisenberg J, Burch WCJr, Carretero C, Chowers $\mathrm{Y}$, et al. Accuracy of capsule colonoscopy in detecting colorectal polyps in a screening population. Gastroenterology. 2015;148(5):94857.e2.

18. Hagel AF, Gabele E, Raithel M, Hagel WH, Albrecht H, de Rossi $\mathrm{TM}$, et al. Colon capsule endoscopy: detection of colonic polyps compared with conventional colonoscopy and visualization of extracolonic pathologies. Can J Gastroenterol Hepatol. 2014;28(2):7782.
19. Holleran G, Leen R, O'Morain C, McNamara D. Colon capsule endoscopy as possible filter test for colonoscopy selection in a screening population with positive fecal immunology. Endoscopy. 2014;46(6):473-8

20. Spada C, Hassan C, Munoz-Navas M, Neuhaus H, Deviere J, Fockens P, et al. Second-generation colon capsule endoscopy compared with colonoscopy. Gastrointest Endosc. 2011;74(3):5819.e1.

21. Eliakim R, Yassin K, Niv Y, Metzger Y, Lachter J, Gal E, et al. Prospective multicenter performance evaluation of the secondgeneration colon capsule compared with colonoscopy. Endoscopy. 2009;41(12):1026-31.

22. Higgins J, Green S. The Cochrane collaboration, Cochrane Handbook for SystematicReviews of Intervention v 5.1.0. 2011, http://handbook-5-1.cochrane.org/. 
Appendix 1. Literature Search Strategies

Search date: February 30, 2018

Databases searched: PubMed, Scopus, Cochrane Library, Science Direct

\section{Search Strategy:}

Pubmed

(((colonoscopy[MeSH Terms] OR colonoscop*[Title/Abstract] OR sigmoidoscopy[MeSH Terms] OR sigmoidoscop*[Title/Abstract]) AND ("second generation colon capsule endoscopy"[Title/Abstract] OR "colon capsule endoscopy"[Title/Abstract] OR "capsule colonoscopy"[Title/Abstract] OR "CCE-2"[Title/Abstract] OR "PCC-2"[Title/Abstract] OR "colon capsule"[Title/Abstract] OR "PCCE-2"[Title/Abstract] OR "pillcam$2 "[$ Title/Abstract])))

Scopus

TITLE-ABS-KEY ("second generation colon capsule endoscopy") OR TITLE-ABS-KEY ("PCC2") OR TITLE-ABS-KEY ("CCE2") OR TITLE-ABSKEY ("pillcam 2") OR TITLE-ABS-KEY ("colon capsule") OR TITLE-ABS-KEY ("colon capsule endoscopy") OR TITLE-ABS-KEY ("capsule colonoscopy") AND TITLE-ABS-KEY (colonoscopy) OR TITLE-ABS-KEY (sigmoidoscopy)

\section{Cochrane Library}

("second generation colon capsule endoscopy": ti,ab,kw or "PCC2":ti,ab,kw or "CCE2":ti,ab,kw or "colon capsule":ti,ab,kw or "colon capsule endoscopy":ti,ab,kw or "capsule colonoscopy":ti,ab,kw) and ("colonoscopy":ti,ab,kw or "sigmoidoscopy":ti,ab,kw)

Science Direct

TITLE-ABSTR-KEY(colonoscop*) or TITLE-ABSTR-KEY(sigmoidoscop*) and TITLE-ABSTR-KEY ("second generation colon capsule endoscopy") or TITLE-ABSTR-KEY(CCE2) or TITLE-ABSTR-KEY(PCC2) or TITLE-ABSTR-KEY ("colon capsule") or TITLE-ABSTR-KEY (pillcam 2) or TITLE-ABSTR-KEY ("colon capsule endoscopy") or TITLE-ABSTR-KEY ("capsule colonoscopy").

Appendix 2. Quality Assessment

The quality of the studies was evaluated by the researcher. In all 8 studies, there was enough information to create a two by two table of the index test results, and these eight studies entered the final stage.

Risk of Bias for studies of Second-generation Colon Capsule Endoscopy (QUADAS-2)

\begin{tabular}{|c|c|c|c|c|}
\hline Author, Year & & Risk of B & & \\
\hline & Patient Selection & Index Test & Reference Standard & Flow and Timing \\
\hline Eliakim (2009) & $\operatorname{High}^{a}$ & Low & Low & High $^{b}$ \\
\hline Spada (2011) & High $^{\text {a }}$ & Low & Low & High $^{b}$ \\
\hline Hagel (2014) & High $^{\text {a }}$ & Low & Low & High $^{b}$ \\
\hline Holleran (2014) & Low & Low & Low & Low \\
\hline $\operatorname{Rex}(201)$ & Unclear & Low & Low & $\operatorname{High}^{\mathrm{b}}$ \\
\hline Morgan (2016) & Unclear & Low & Low & High $^{b}$ \\
\hline Igawa (2017) & Low & Low & Low & High $^{\text {b }}$ \\
\hline Parodi (2018) & Low & Low & Low & Low \\
\hline
\end{tabular}

Abbreviations: QUADAS-2, Quality Assessment of Diagnostic Accuracy Studies.

${ }^{a}$ Patients were not selected randomly or consecutively.

${ }^{\mathrm{b}}$ Not all patients were included in the analysis. 